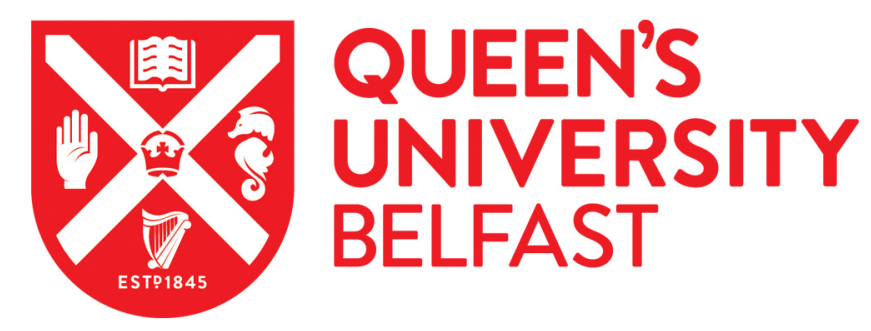

\title{
Evidence for co-selection of antibiotic resistance genes and mobile genetic elements in metal polluted urban soils
}

Zhao, Y., Cocerva, T., Cox, S., Tardif, S., Su, J. Q., Zhu, Y. G., \& Brandt, K. K. (2019). Evidence for co-selection of antibiotic resistance genes and mobile genetic elements in metal polluted urban soils. Science of the Total Environment, 656, 512-520. https://doi.org/10.1016/j.scitotenv.2018.11.372

Published in:

Science of the Total Environment

Document Version:

Peer reviewed version

Queen's University Belfast - Research Portal:

Link to publication record in Queen's University Belfast Research Portal

Publisher rights

Copyright 2018 Elsevier

This manuscript is distributed under a Creative Commons Attribution-NonCommercial-NoDerivs License

(https://creativecommons.org/licenses/by-nc-nd/4.0/), which permits distribution and reproduction for non-commercial purposes, provided the author and source are cited.

\section{General rights}

Copyright for the publications made accessible via the Queen's University Belfast Research Portal is retained by the author(s) and / or other copyright owners and it is a condition of accessing these publications that users recognise and abide by the legal requirements associated with these rights.

Take down policy

The Research Portal is Queen's institutional repository that provides access to Queen's research output. Every effort has been made to ensure that content in the Research Portal does not infringe any person's rights, or applicable UK laws. If you discover content in the Research Portal that you believe breaches copyright or violates any law, please contact openaccess@qub.ac.uk. 
1 Evidence for co-selection of antibiotic resistance genes and mobile genetic elements in metal polluted urban

2 soils

3 Yi Zhao ${ }^{\mathrm{a}, *}$, Tatiana Cocerva ${ }^{\mathrm{b}}$, Siobhan Cox $^{\mathrm{b}}$, Stacie Tardif ${ }^{\mathrm{a}}$, Jian-Qiang Suc ${ }^{\mathrm{c}}$, Yong-Guan $\mathrm{Zhu}^{\mathrm{c}, \mathrm{d}}$, Kristian Koefoed

$4 \quad$ Brandt $^{\mathrm{a}, \mathrm{e}} *$

$5 \quad{ }^{a}$ Department of Plant and Environmental Sciences, Faculty of Science, University of Copenhagen, Thorvaldsensvej

6 40, 1871 Frederiksberg, Denmark

$7 \quad{ }^{\mathrm{b}}$ School of Natural and Built Environment, Queen's University of Belfast, David Keir Building, Stranmillis Road

8 Belfast, BT9 6AX, United Kingdom

$9{ }^{\mathrm{c}}$ Key Laboratory of Urban Environment and Health, Institute of Urban Environment, Chinese Academy of Sciences, 101799 Jimei Road, Xiamen 361021, China

$11{ }^{\mathrm{d}}$ State Key Laboratory of Urban and Regional Ecology, Research Center for Eco-Environmental Sciences, Chinese

12 Academy of Sciences, Beijing 100085, China

$13{ }^{\mathrm{e}}$ Sino-Danish Centre for Education and Research, Huairou District, Beijing, China

14

$15 *$ Corresponding Authors

16 Yi Zhao, Section for Microbial Ecology and Biotechnology, Department of Plant and Environmental Sciences,

17 University of Copenhagen, Thorvaldsenvej 40, DK-1871 Frederiksberg C, Denmark

18 E-mail: y.zhao@plen.ku.dk, Phone: +45-35334549

19 Kristian Koefoed Brandt, Section for Microbial Ecology and Biotechnology, Department of Plant and

20 Environmental Sciences, University of Copenhagen, Thorvaldsenvej 40, DK-1871 Frederiksberg C, Denmark

21 E-mail: kkb@plen.ku.dk, Phone: +45-35332612 


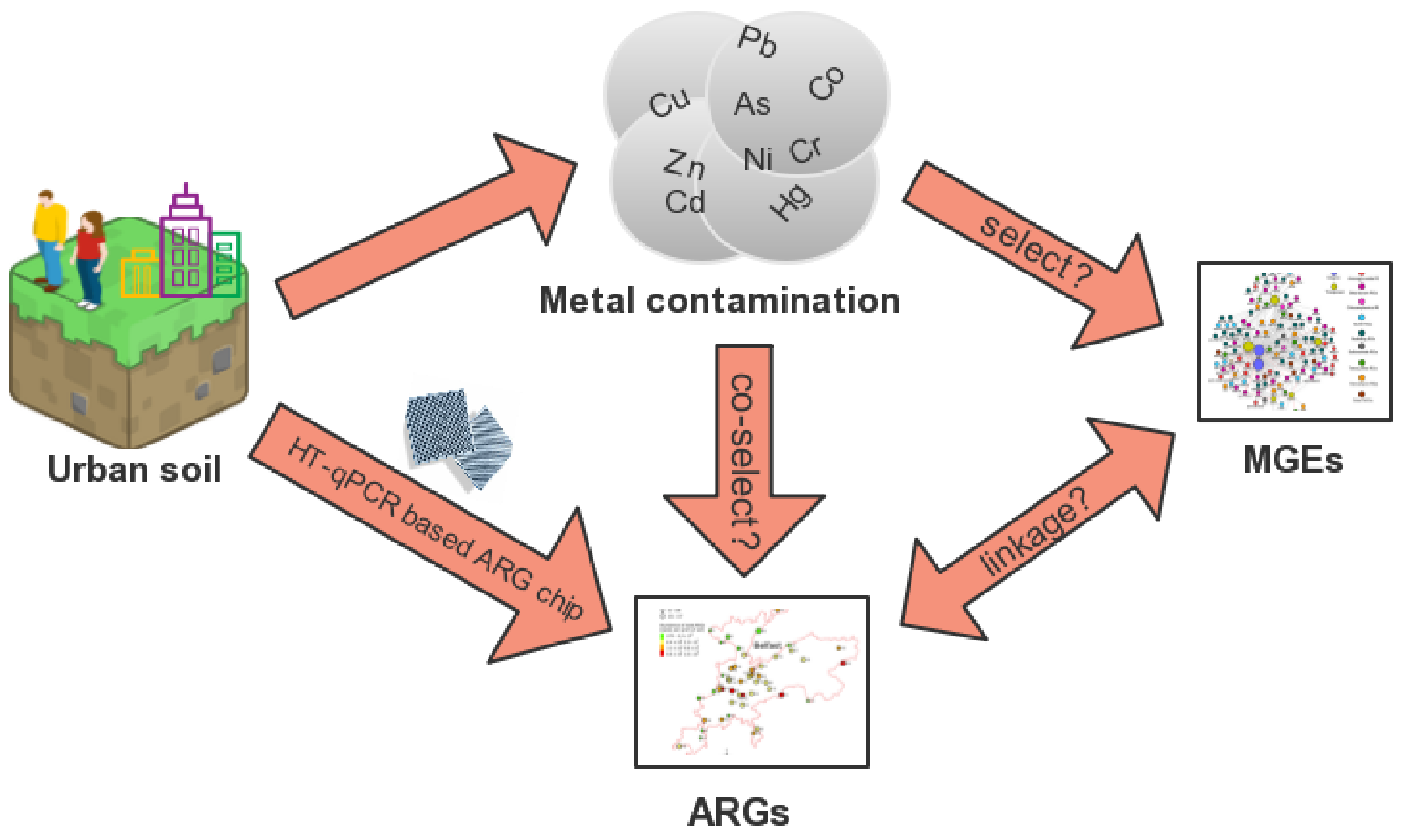




\section{Highlights:}

1. Fifty archived urban soils from the Belfast area Tellus Survey were analyzed.

2. Antibiotic resistance determinants were profiled by high throughput qPCR chip.

3. Evidence for metal-induced co-selection of antibiotic resistance genes (ARGs).

4. Total ARGs were positively correlated with total mobile genetic elements.

5. Metals may confer persistent selection pressures for ARGs in urban soils. 


\section{$1 \quad$ Abstract}

2 Antibiotic resistance genes (ARGs) constitute emerging environmental pollutants and pose risks to public

3 health. Toxic metals are known to select for metal-resistant bacteria in metal-contaminated soils, but there

4 is growing concern that metal contaminants can also act as co-selective agents thereby causing

5 environmental proliferation of antibiotic resistance. In this study, we quantified ARGs and selected

6 mobile genetic elements (MGEs) known to constitute potential ARG hosts in 50 archived urban and

7 suburban soils from the Belfast metropolitan area using a high-throughput qPCR ARG chip. ARG

8 prevalence was linked to concentrations of individual metals and a soil metal toxicity index calculated

9 based on the relative toxicity of different metals to soil microbial processes. A total of 164 ARGs were

10 detected across the 50 soils analyzed with an average absolute abundance of $3.4 \times 10^{7}$ ARG gene copies

11 per gram of soil. A significant correlation between abundance of ARGs and MGEs was observed,

12 suggesting the importance of horizontal gene transfer for ARG dissemination. Network analysis revealed

13 significant co-occurrence patterns between specific metals ( $\mathrm{As}, \mathrm{Cd}, \mathrm{Co}, \mathrm{Cr}, \mathrm{Cu} . \mathrm{Hg}, \mathrm{Ni}$ and $\mathrm{Zn}$ ) and

14 associated ARGs. Path analysis further indicated that the soil metal toxicity index significantly affected

15 the number of detected ARGs $(\lambda=0.32, P<0.001)$ and the abundance of metal co-occurring ARGs $(\lambda=$

$160.612, P<0.001)$ via effects on MGEs. Collectively, our results indicate a role of soil metals in co-

17 selection of ARGs and MGEs in urban and semi-urban soils and suggest a risk for environmental ARG

18 dissemination via horizontal gene transfer.

\section{Keywords}

21 Antibiotic resistance genes, mobile genetic elements, co-selection, metal toxicity, qPCR chip, urban soils 


\section{Introduction}

25 The rapid emergence of antibiotic-resistant bacteria is occurring worldwide, posing threats to global

26 public health, food security and development (Ventola, 2015). According to the World Health

27 Organization (WHO), a post-antibiotic era is emerging, in which antibiotic resistance threatens the

28 effective prevention and successful treatment of an ever-increasing range of bacterial infections. The

29 critical role of the environment for development and dissemination of antibiotic resistance has now been

30 recognized (Ashbolt et al., 2013). Consequently, antibiotic resistance genes (ARGs) and mobile genetic

31 elements carrying these genes can be regarded as emerging environmental pollutants (Gillings et al., 2008;

32 Pruden et al., 2006).

34 The widespread use of antibiotics is generally considered to be the primary cause for elevated levels of

35 ARGs in pathogenic bacteria (Ventola, 2015), but there is growing concern that contaminants such as

36 metals and biocides may also co-select for antibiotic resistance (Baker-Austin et al., 2006; Berendonk et

37 al., 2015; Hoffman et al., 2005; Pal et al., 2017; SCENIHR, 2009). Co-selection of antibiotic and metal(loid) resistance have been associated with arsenic (As), cadmium (Cd), cobalt (Co), chromium (Cr), copper $(\mathrm{Cu})$, mercury $(\mathrm{Hg})$, nickel $(\mathrm{Ni})$, lead $(\mathrm{Pb})$ and zinc $(\mathrm{Zn})$ (Knapp et al., 2011; Pal et al., 2017; Pal et al., 2015; Seiler and Berendonk, 2012; Yazdankhah et al., 2014). Several co-selection mechanisms are

41 known (Baker-Austin et al., 2006). The genes encoding resistance to antibiotics and metals may for

42 instance be found on the same mobile genetic elements (plasmid, integron or transposon), and this

43 physical linkage results in co-resistance. Cross-resistance is another co-selection mechanism which occurs 44 when single genes encode resistance to both antibiotics and metals.

46 The relative importance of antibiotics and co-selecting agents for the selection of antibiotic resistance is 47 likely to differ between different environments. Antibiotic residues primarily accumulate to toxic levels 
able to strongly select bacterial communities in habitats where antibiotics are used by humans (e.g.,

49 human or animal gut), whereas antibiotics only rarely accumulate to toxic levels in soil or water (Brandt

50 et al., 2015). By contrast, metals frequently accumulate to toxic levels in some environmental

51 compartments including both agricultural and urban soils (Brandt et al., 2010; Berg et al., 2012; Imfeld et

52 al., 2011; McLaughlin and Smolders, 2001). Indeed, toxic metals may in some cases provide stronger and

53 more persistent selective pressures for environmental selection of antibiotic resistance as compared to

54 antibiotic residues (Song et al., 2017). Consequently, metal-induced co-selection for ARGs in metal

55 contaminated environments represents a risk factor for the expansion of the soil bacterial resistome and

56 may thus represent a barrier for reversal of antibiotic resistance even if antibiotic residues are prevented

57 from reaching the environment.

59 Continuous accumulation of metal(loid) contaminants widely occurs in urban soils (Luo et al., 2012).

60 Over half of the world's population currently lives in urban areas, and the urban population continues to

61 grow (United Nations, 2014) suggesting increasingly important linkages between urban environmental

62 quality and human health (Li et al., 2018). Due to rapid urbanization and intensive anthropogenic activity,

63 a massive volume of potential selective agents (such as heavy metals) and microbes carrying ARGs

64 swarm into urban soils and successfully persist, increasing the level of ARG pollution in urban

65 environments (Wang et al., 2014). These ARGs spread amongst humans and in the environment by

66 horizontal gene transfer (HGT), developing into pathogenic antibiotic-resistant bacteria (pARB) and

67 thereby raising the risk of failure of antibiotic treatments (Zhu et al., 2018). The linkage between soil

68 metals and ARGs from urban and industrially polluted soils has been observed in previous studies (Knapp

69 et al., 2017, Berg et al. 2010). However, only a few metals and a limited number of ARGs were targeted

70 and comprehensive evidence for the ability of metals to co-select antibiotic-resistance in urban soils is

71 still largely lacking (Larsson et al., 2018). Therefore, monitoring ARG distribution in urban environments

72 and its association with metals as co-selective agents is necessary. 
74 In this study, we profiled ARGs in metal-contaminated soils within an urban area to improve our 75 understanding of the role of metal contaminations in developing ARGs. To this end, 50 archived soils 76 across the urban area of Belfast, Northern Ireland with a gradient of various metal contaminations were

77 selected and examined using a high-throughput qPCR based ARG chip. The ARG profile was

78 subsequently linked to MGEs and metal contamination by multivariable statistical analyses and network

79 analysis. Cluster analysis, permanova test with land use and distance-decay analysis was applied to depict

80 the influence of geographic factors (spatial location) on ARG distribution. The path analysis was further

81 performed to test our hypotheses of metal-induced co-selection on ARGs.

82

\section{2. Materials and Methods}

84 2.1. Study area

Belfast is the capital and the largest city in Northern Ireland with a population of approximately 700000 (NISRA, 2016). During the 18th and 19th centuries, Belfast grew to be the leading industrial city in

87 Ireland, with thriving linen and shipbuilding industries. Belfast continued to play an important role 88 throughout the industrial revolution in the $19^{\text {th }}$ century and is also historically recognized for tobacco89 processing, rope making, glass manufacturing, tobacco production and distilleries (Royle et al., 2007).

90 Concentrations of metal(loid)s in the Belfast area have been shown to act as an 'urbanization tracer'

91 (Mcllwaine et al., 2017) and differential metal(loid) concentrations can, therefore, be largely attributed to

92 anthropogenic contamination. By contrast, anthropogenic contamination of the Belfast area soils with

93 antibiotics or ARGs can generally be considered negligible. Human fecal wastes are almost exclusively

94 released to aquatic recipients through wastewater collection and treatment processes (EMEA, 2006).

95 Leakage of untreated wastewater from the collection network into soil could potentially provide a route

96 for antibiotics and ARGs to enter the soil. However, the collection network is at a greater depth than the 
97 soils investigated in this study (5-20 cm depth), and significant top soil contamination is therefore highly

98 unlikely. We therefore assume that ARGs present in the sampled top soils of the Belfast area were

99 primarily derived from the natural, 'background' antibiotic resistome (e.g. ARGs in soil-dwelling bacteria

100 producing or degrading antibiotics; (D’Costa et al., 2007; Dantas et al., 2008)) with potential

101 contributions from other diffuse sources (e.g. ARGs in fecal matter from wildlife, rain water, or particles

102 deposited via air). Hence, the metropolitan area of Belfast provides an opportunity to evaluate the ability

103 of soil metal(loid)s to co-select antibiotic resistance. The boundaries of the study area have been defined

104 using the Corine land cover data (European Environment Agency, 2012) satellite images and the spatial

105 distribution of the available urban soil samples.

107 2.2. Soil collection

108 The Tellus geochemical and geophysical survey was undertaken across the entire region of Northern 109 Ireland by the Geological Survey of Northern Ireland (GSNI) between 2004 and 2007. Shallow soil 110 samples $(5-20 \mathrm{~cm})$ from 1166 sampling locations were collected and archived at room temperature $(<$ $11125^{\circ} \mathrm{C}$ ). Full details of the sampling strategy are described in a previous study (Smyth, 2007). In this study, 112 a total of 50 sampling locations were selected (Figure 1a) and their archived urban soils (Knights, 2006) 113 were retrieved from the GSNI Tellus survey archive in October 2016. Original sampling coordinates are

114 listed in Table S1. Sample selection targeted a broad spectrum of toxic elements, with a wide range of 115 concentrations, and included a variety of different land uses while ensuring samples were spatially 116 distributed across the city.

\subsection{Soil chemical characterization}

119 Archived metal concentration data ( $\mathrm{As}, \mathrm{Cd}, \mathrm{Co}, \mathrm{Cr}, \mathrm{Cu}, \mathrm{Hg}, \mathrm{Ni}, \mathrm{Pb}$ and $\mathrm{Zn}$ ) were retrieved from the 120 Tellus database for downstream analyses. The spatial distribution of these elements across Belfast has 
121 been reported previously (McIlwaine et al., 2017). Concentrations of As in soils were found to be

122 controlled by anthropogenic inputs. By contrast, concentrations of $\mathrm{Cu}$ and $\mathrm{Zn}$ were influenced by both

123 anthropogenic and geogenic inputs, while concentrations of $\mathrm{Ni}$, $\mathrm{Co}$ and $\mathrm{Cr}$ were mainly attributed to

124 geogenic sources (McIlwaine et al., 2017).

126 A metal toxicity index ( $\left.\mathrm{TI}_{\text {metals }}\right)$ was calculated for each soil sample to provide a normalized measure of

127 the bacterial selection pressure posed by the toxic metals present in each sample. $\mathrm{TI}_{\text {metals }}$ was calculated 128 based on previously recorded effects of individual metal(loid)s ( $\mathrm{As}, \mathrm{Cd}, \mathrm{Co}, \mathrm{Cr}, \mathrm{Cu}, \mathrm{Hg}, \mathrm{Ni}, \mathrm{Pb}$ and $\mathrm{Zn}$ ) 129 on soil microbial processes (Welp, 1999) following a previously established procedure (Azarbad et al., 130 2015; Stefanowicz et al., 2008): $\mathrm{TI}_{\text {metals }}=\sum\left(\mathrm{C}_{\mathrm{i}} / \mathrm{EC}_{50 \mathrm{i}}\right)$, where $\mathrm{C}_{\mathrm{i}}$ equals the total concentration of the 131 element $\mathrm{i}$ in the soil and $\mathrm{EC}_{50 \mathrm{i}}$ equals the half-maximal effective concentration for that particular element $\mathrm{i}$ 132 (Welp, 1999).

Archived soil $\mathrm{pH}$ and land use data were also retrieved from the Tellus database (Table S1). Full details 135 of the analytical methods used and quality assurance/quality control procedures adopted in the Tellus 136 geochemical survey can be found in a previous study (Smyth, 2007).

\subsection{DNA extraction}

139 The 50 selected soil samples were retrieved from the Tellus soil archive and aseptically weighed into 140 prepared sterile plastic bags. A total of 250 - $400 \mathrm{mg}$ of dry soil was transferred into PowerBead Tubes 141 (MoBio) and incubated for rehydration at room temperature for 20-30 minutes. DNA was extracted from 142 rehydrated soil using MoBioPowerSoil ${ }^{\circledR}$ DNA Isolation Kit according to the instruction manual. The concentration and purity of DNA were checked using ultraviolet absorbance (ND1000, Nanodrop, 
144 Thermo Fisher Scientific). DNA was eluted in $100 \mu$ l elution buffer and stored at $-20{ }^{\circ} \mathrm{C}$ for downstream 145 analysis. Long-term storage has been proven to not cause bias in DNA results (Tzeneva et al., 2009, 146 Knapp et al., 2010).

\subsection{High-throughput qPCR}

149 A total of 296 primer sets (Table S2) were used to examine Belfast urban soils. These 296 primer sets 150 targeted antibiotic resistance genes (285 primer sets), mobile genetic elements (10 primer sets) and a $16 \mathrm{~S}$ rRNA gene as a reference gene (Zhao et al., 2018; Zhu et al., 2017). Collectively, the targeted ARGs confer resistance to all major classes of antibiotics including aminoglycoside, beta-lactamase, chloramphenicol, macrolide-lincosamide-streptogramin B (MLSB), multidrug, sulfonamide, tetracycline

154 and vancomycin. Targeted mobile genetic elements included transposase genes (8 primer sets) and Class 1551 integron-integrase gene (2 primer sets). The HT-qPCR was performed with an HT-qPCR based ARG 156 chip using the WaferGen SmartChip Real-time PCR system. Negative controls were included. The 157 thermal cycle consisted of $10 \mathrm{~min}$ at $95^{\circ} \mathrm{C}$, followed by 40 cycles of denaturation at $95{ }^{\circ} \mathrm{C}$ for $30 \mathrm{~s}$ and 158 annealing at $60^{\circ} \mathrm{C}$ for $30 \mathrm{~s}$. Melting curve analyses were automatically conducted by Wafergen 159 SmartChip qPCR software.

All HT-qPCR were performed in technical triplicates with negative control. The data from reaction wells with $r^{2}$ smaller 0.99 were discarded. Only data for samples with three technical replicates that all 163 generated amplification products were regarded as positive detection and used in further data analysis.

164 Relative copy number was calculated based on previously published method (Looft et al., 2012): relative 165 gene copy number $=10_{\mathrm{T}}^{\left(31-\mathrm{C}_{\mathrm{T}}\right) /(10 / 3)}$, where $\mathrm{C}_{\mathrm{T}}$ refers to the $\mathrm{qPCR}$ results and 31 refers the cut-off point. The normalized abundance of a gene (copies per $16 \mathrm{~S}$ rRNA) was calculated by dividing relative gene copy

167 number of the gene by relative copy number of reference gene $16 \mathrm{~S}$ rRNA. 
169 Absolute 16S rRNA copy numbers (copies per gram of soil) were determined using the standard curve 170 method on a Roche 480 system. Each $20 \mu \mathrm{l}$ qPCR reaction mixture consisted of $10 \mu 12 \times$ LightCycle 480

171 SYBR Green I Master, one $\mu \mathrm{g} \mu \mathrm{l}^{-1}$ bovine serum albumin, one $\mu \mathrm{M}$ of each primer, one ng $\mu \mathrm{l}^{-1}$ DNA as

172 template and six $\mu$ nuclease-free PCR-grade water. The thermal cycle consisted of a 10 min enzyme

173 activation at $95{ }^{\circ} \mathrm{C}$, followed by 40 cycles of denaturation at $95^{\circ} \mathrm{C}$ for $30 \mathrm{~s}$, annealing at $60{ }^{\circ} \mathrm{C}$ for $30 \mathrm{~s}$

174 and extension at $72{ }^{\circ} \mathrm{C}$ for $15 \mathrm{~s}$. A plasmid control containing a cloned and sequenced 16S rRNA gene

175 fragment $\left(1.39 \times 10^{10}\right.$ copies per liter) was used to generate calibration curves from a tenfold dilution for 176 standard calculation. All qPCRs were performed in technical triplicates with negative controls. Absolute 177 ARG copy numbers were calculated by transforming relative copy numbers by normalization from 178 absolute 16S rRNA gene copy number.

All HT-qPCR data filtration and calculations were performed using Microsoft Excel 2010. Bar charts and scatter diagrams were generated using Origin Pro 9.1. Correlation analyses and significance tests were performed using IBM SPSS Statistics 22. Heatmaps were generated using HemI 1.0 (Deng et al., 2014).

184 Shannon H index was determined using PAST Statistics Software (Hammer et al., 2001). The distancedecay analysis and permanova test were conducted using R 3.4.1 with the vegan package (Oksanen et al.,

186 2007). The co-occurrence patterns between ARGs (normalized abundance) and MGEs (normalized

187 abundance)/metals (total concentration) were explored using network analysis. To visualize the 188 correlations in the network interface, a correlation matrix was constructed using all pairwise Pearson's 189 rank correlations. Only correlations with Pearson's $r>0.7$ (or $<-0.7$ ), a significance level of $P<0.05$, 190 and p-values lower than the critical value calculated by the Benjamini-Hochberg procedure (false 191 discovery correction) were considered robust and used for forming the co-occurrence networks. The 
network structure was confirmed by randomization procedure from randomized data. Network visualization was performed in Cytoscape 3.6.0 (Shannon et al., 2003). For spatial data representation, maps were produced using the ArcGIS software ArcMap version 10 (ESRI, 2010).

The path analysis, as a special case of structural equation model (SEM), has been proven useful as a 197 statistical tool to explore the complex networks of causal relationships ecosystems (Eisenhauer et al., 198 2015). In this study, it was performed to evaluate the overall effect of soil metal contamination 199 (represented by $\mathrm{TI}_{\text {metals }}$ ) on $\mathrm{ARG}$ patterns as represented by both the number of detected ARGs and the 200 normalized abundance of all co-occurring ARGs using SPSS AMOS. The path model was established 201 based on the following theoretical assumptions: (i) metal contamination may directly influence ARG 202 patterns by acting as a direct selective agent; (ii) metal contamination may indirectly affect ARG patterns 203 through MGE associated co-selection processes, with co-resistance as a mechanism. The data were fitted 204 to the estimated model using a maximum-likelihood estimation method. The model fit was tested and an 205 overall goodness-of-fit of the model was indicated by satisfaction of the following criteria: (i) non206 significant Chi-square value $(P>0.05)$; (ii) low root mean square error of approximation as absolute fit 207 index (RMSEA < 0.08); (iii) high increment fit index (CFI, GFI, TLI, NFI > 0.95; CFI as comparative fit 208 index, GFI as goodness of fit, TLI as Tucker-Lewis index and NFI as Normed-fit index). The disturbance 209 terms (also called the residual error terms) were added into the model to reflect the unexplained variance 210 and measurement error. The path coefficients (standardized regression weights) and significance were 211 calculated in an SPSS AMOS, showing the effect of an independent variable on a dependent variable in 212 the path model. The standardized direct, indirect and total effects were automatically calculated using 213 SPSS AMOS following the method published previously (Finney, 1972). 
217 A total of 175 genes (164 ARGs, eight transposase genes, two Class 1 integron-integrase genes and the 218 16S rRNA gene) were detected by the HT-qPCR chip in the 50 studied urban soils (Figure 1). The 219 detected ARGs represented most major resistance mechanisms including antibiotic deactivation (43\%), 220 efflux pumps (34\%) and cellular protection (19\%) (Figure 1b) and confer resistance to most major classes 221 of antibiotics administered to humans and animals, including aminoglycosides, beta-lactams, 222 chloramphenicols, MLSB, sulfonamides, tetracyclines, vancomycin and multidrug. Almost half of the 223 detected ARGs confer resistance to beta-lactams (23\%) and multidrug (23\%) (Figure 1c). The number of 224 detected ARGs in the Belfast urban area ranged from 8 to 137 with the average at 67 (Figure 1a). The 225 Shannon diversity H index of ARGs varied from 1.2 to 3.4 in Belfast urban samples (Figure S1). To 226 compare the spatial similarity of ARG patterns, we examined the presence and absence of ARGs across 227 all samples. Only two shared core ARGs ( $m p h A-02$ and $c p h A-01)$ conferring resistance to macrolide and 228 beta-lactam antibiotics were found in all samples.

The absolute abundance of ARGs in Belfast urban soils varied over six orders of magnitude $\left(6.8 \times 10^{2}\right.$ to $2311.7 \times 10^{8}$ copies per gram of soil) with an average of $3.4 \times 10^{7}$ (Figure 1a). The predominant ARGs 232 encoded beta-lactam, multidrug, aminoglycoside or chloramphenicol resistance (Figure S2). The three 233 most abundant ARGs were mexF, $c p h A-01$ and $\operatorname{cm} x(A)$. The mexF gene, which encodes a multidrug 234 resistance efflux pump for chloramphenicol and fluoroquinolone, was detected in 49 soil samples at 5 $235229 \times 10^{7}$ copies per gram of soil. The $c p h A$ gene confers resistance to different beta-lactams antibiotics 236 (penicillin, cephalosporin and carbapenem) via hydrolysis of the beta-lactam ring and was detected in all 23750 soils with an average abundance of $6.6 \times 10^{6}$ copies per gram of soil. The $\operatorname{cm} x(A)$ gene encodes a 238 chloramphenicol exporter and was found in 49 samples, varying in abundance from $2-43 \times 10^{7}$ copies 239 per gram of soil. 
241 To better explore the prevalence of ARGs within the studied soil bacterial communities, the absolute

242 abundance of ARGs and MGEs was normalized relative to the abundance of the 16S rRNA gene.

243 Bacterial abundances in soils were in the range of $8.7 \times 10^{3}$ to $9.0 \times 10^{8}$ with an average of $2.2 \times 10^{8}$

244 copies per gram. The normalized ARG abundance in 50 soils varied from 0.06 to 0.77 with an average of $245 \quad 0.15$ ARG copies per 16S rRNA gene.

247 We further investigated the spatial distribution of ARGs with distance-decay analysis and cluster analysis.

248 However, our results show that ARG distribution in the Belfast urban area was unlikely to have been

249 driven by geographic factors. The geographic distance did not show any significant correlation with the

250 similarity of ARG communities between samples (Pearson's $r=-0.026, P=0.355$ ) (Table S3). Likewise,

251 land use at the time of soil sampling could not explain the observed ARG patterns. Combining the cluster

252 analysis with a heatmap to visualize the ARG profiles in different land uses, we thus did not find any

253 significant effect of land use (cluster) on the ARG distribution in Belfast urban soils (Figure S3\&4). This

254 conclusion was further confirmed by permanova test $\left(R^{2}<0.02, P>0.05\right.$; Table S4). Both results

255 indicated the inconsequential role that geographic factors played in determining the fate of ARGs in

256 Belfast urban soils.

258 3.2. MGEs and their associations with ARGs

259 A total of two integron genes and eight transposon genes were targeted and detected in this study. The

260 total absolute abundance of these MGEs ranged from 2-38 $\times 10^{7}$ copies per gram of soil with an average

261 of $3.4 \times 10^{6}$. The normalized abundance of MGEs ranged from 0.004 to 0.069 copies per 16S rRNA gene

262 with average at 0.014 . Class 1 integron, intI-1, was found in all 50 soils. Significant correlations were

263 found between MGEs and ARGs (Figure 2). The normalized abundance of MGEs was positively 
correlated with the number of ARGs detected (Pearson's $r=0.57, P<0.001$ ), as well as normalized abundance of ARGs (Pearson's $r=0.66, P<0.001$ ) (Figure 2a). Positive correlations were also found between the absolute abundance of ARGs and the MGEs: Class 1 integrons (Pearson's $r=0.97, P<0.001$ ) and transposons (Pearson's $r=0.66, P<0.001$ ) (Figure S5).

The co-occurrence pattern between specific ARGs and MGEs were revealed by network analysis based on Pearson correlations $(r>0.7, P<0.05)$ (Figure $2 b)$. The network consists of 130 nodes corresponding to 8 MGEs and 122 ARGs. A total of 358 strong correlations between these MGEs and ARGs were found,

272 including 334 positive correlations and 24 negative correlations. MGEs including integrons and 273 transposons both exhibited a co-occurrence pattern with different types of ARGs. A total of 81 ARGs 274 were positively correlated with the class 1 integron, intI-1, while 77 ARGs were positively correlated with 275 the clinical class 1 integron, $c$ IntI-1. For transposons, 66 ARGs were found positively correlated to tnpA 276 and IS613 genes. Among the 358 correlations between ARGs and MGEs, 31\% were contributed by 277 multidrug-resistant genes, while beta-lactam, MLSB, vancomycin, aminoglycoside, tetracycline and 278 chloramphenicol resistant genes accounted for $20 \%, 12 \%, 12 \%, 7 \%, 6 \%$ and $2 \%$, respectively.

281 The soil samples profiled for ARGs and MGEs were contaminated to varying degrees by metals. The 282 metals with the potential of co-selection for ARGs and their concentration ranges in the soil samples were 283 shown in Table 1. The co-occurrence pattern between metals and ARGs was further explored by network 284 analysis based on Pearson's correlation $(r>0.7, P<0.05)$ (Figure 3). The network consists of 25 nodes 285 including eight metals and 17 ARGs. A total of 24 significant positive correlations were found between 286 metals and ARGs. No significant negative correlation was found between metals and ARGs. As, Cd, Co, $287 \mathrm{Cr}, \mathrm{Cu}, \mathrm{Hg}, \mathrm{Ni}$ and $\mathrm{Zn}$ all exhibited co-occurrences with specific ARGs. Zinc was found to co-occur with 
eight resistance genes conferring resistance to aminoglycosides (4), multidrug (3) and beta-lactam antibiotics (1). Copper co-occurred with aminoglycoside resistance genes (aadA and aac) and MLSB resistance genes (mefA). The number of ARGs that co-occurred with $\mathrm{Cd}, \mathrm{Co}, \mathrm{Ni}, \mathrm{Hg}, \mathrm{Cr}$ and $\mathrm{As}$ were 3,3 , 2, 2, 2 and 1, respectively. These metal(loid)s all co-occurred with 17 specific ARGs conferring resistance to aminoglycosides, beta-lactams, MLSBs, multidrug, tetracycline and vancomycin. Among the 24 connections, almost half were contributed by a combination of aminoglycoside (25\%) and multidrug 294 resistance genes (21\%).

\subsection{The effects of metal toxicity index and MGEs on ARGs}

297

To further assess the effects of metals and MGEs on ARGs, structural equation model (SEM) based path analysis was performed with a multiple-pathways model based on the theoretical assumptions outlined in section 2.6 (Figure 4a). The path analysis indicated that the degree of soil metal contamination (metal toxicity index) had a significant direct positive association on normalized abundance of co-occurring ARGs (copies per 16S rRNA gene) $(\lambda=0.187, P<0.01)$ and a significant indirect positive effect on number of detected ARGs $(\lambda=0.251, P<0.001)$ (Figure $4 \mathrm{~b}$ ) and normalized abundance of co-occurred ARGs (copies per 16S rRNA gene) $(\lambda=0.426, P<0.001)$ (Figure 4c). The total standardized effects of metal toxicity index on the number of detected ARGs and normalized abundance of co-occurring ARGs (copies per 16S rRNA gene) were 0.323 and 0.612 , respectively. This suggests that increase of one unit of one metal toxicity index resulted in 0.323 more numbers of ARGs detected and 0.612 more copies of cooccurred ARGs per 16S rRNA gene. Metal toxicity changed MGE abundances in soil $(\lambda=0.521, P<$ 0.001) and subsequently influenced the number of detected ARGs and abundance of co-occurring ARGs $(\lambda=0.483, P<0.001$ and $\lambda=0.817, P<0.001)$ (Figure 4a). Metal toxicity index and MGE abundance both had a total positive effect on the number of detected ARGs and abundance of co-occurred ARGs. The path analysis results were further tested and confirmed by correlation analysis. The correlation analysis showed significant positive correlations among metal toxicity index, the abundance of MGE, 
number detected ARGs and abundance of co-occurring ARGs (Figure S6), which further confirmed the

314 positive association between metals and ARGs via MGEs. Significant positive correlations were also

315 found between soil $\mathrm{pH}$ and the number of detected ARGs (Pearson's $\mathrm{r}=0.329, P<0.05$ ), and between

316 the absolute abundance of the 16S rRNA gene and total ARGs (copies per gram) (Pearson's $r=0.905, P$

$317<0.001)$.

\section{Discussion}

4.1. Evidence for metal-induced co-selection of ARGs in urban soils

321 To the best of our knowledge, this present study provides the most comprehensive investigation of the 322 ability of metal contamination to affect the distribution of ARGs in urban soils to date. The co-

323 occurrence between specific metal contaminants and specific ARGs together with the significant positive 324 effect of overall soil metal loading (metal toxicity index) on soil ARGs are key findings and suggests co325 selection of metals and ARGs (Figure $3 \& 4$ ). Not only was a diverse range of ARGs detected, many of 326 which displayed significant co-occurrence patterns with both specific metals and overall metal load 327 (metal toxicity index), but we were also able to identify a potential causal link between soil metals and 328 ARGs. Hence, observed ARG patterns could not be explained by current land use or geographic location 329 and with the possible exception of the two included pasture soils (Table S1), the studied soils were 330 generally unlikely to have received significant recent point source inputs of fecal materials from humans 331 or animals treated with antibiotics. Soil $\mathrm{pH}$ also affected observed ARG patterns; this could most likely be 332 attributed to the known abilities of $\mathrm{pH}$ to modulate bacterial community composition (Rousk et al., 2010) 333 and the bioavailability/toxicity of metals (Smolders et al., 2009). 
Although our study was not specifically designed to compare the relative importance of different coselection mechanisms (Baker-Austin et al., 2006), it clearly demonstrated co-selection of ARGs and MGEs (Figure 4). The strong linkages between metal toxicity index, MGEs and ARGs indicate a significant metal impact on both the diversity and abundance of ARGs via MGEs (Figure 4). According to our results of path analysis, $78 \%$ of the total effect of metal toxicity on the number of detected ARGs

341 and $69 \%$ of the total effect of metal toxicity on the abundance of co-occurring ARGs were observed to

342 occur via MGEs. The majority of co-occurring ARGs with metals were found to also co-occur with

343 MGEs, suggesting an underlying metal-driven co-selection process with co-resistance (i.e. linkage of

344 genes conferring resistance to metals and antibiotics on the same genetic element) as the major

345 mechanism for most studied ARGs that do not have any known roles in bacterial metal resistance.

346 However, the resistance genes $a c r F$, adeA, $\operatorname{tg} B$, qacEA1, $\operatorname{rarD}$, tetPA and mefA encode efflux pumps as

347 their resistance mechanism and cross-resistance with other classes of antimicrobial agents via efflux

348 cannot be ruled out. For instance, the multi-drug resistance pumps encoded by the genes acrF, adeA, 349 qacE $\triangle 1 \mathrm{rarD}$ and $\operatorname{tg} B$ can export both metals and antibiotics for detoxification purposes (Mata et al., 350 2000).

352 The ability of soil bacteria to transfer ARGs to pathogenic bacteria of clinical relevance is of considerable 353 public health concern (Forsberg et al., 2012, Ashbolt et al., 2013, Graham et al., 2016). Importantly, our 354 study indicates that urban soil metal pollution co-selected ARGs that may be prone to horizontal gene 355 transfer between different species of bacteria. Results of correlation analysis, network analysis and path 356 analysis all showed that an increase in MGE abundance was strongly correlated with an increase in ARG 357 diversity and abundance (Figure 2, 4 \& S6). The co-occurrence pattern of ARGs and MGEs revealed by 358 network analysis showed several clusters within the network. Resistance genes such as aac and aad genes, 359 known to be carried within integron gene cassettes (An et al., 2018; Partridge et al., 2009), were strongly correlated with the class 1 integron gene IntI-1, clinical class 1 integron gene $c$ IntI- 1 and transposon 
genes tnpA and IS613 (Figure 2). The clinical class 1 integron-integrase gene, cIntI-1, exhibits rapid responses to various environmental pressures (including toxic metals) and thus has been proposed as a marker for anthropogenic pollution and as an emerging pollutant (Gillings et al., 2015; Gillings, 2018).

364 The significant correlation and co-occurrence pattern between the clinical class 1 integron-integrase gene 365 (cIntI-1) and ARGs (Table S5 \& Figure 2) may therefore suggest that metal contamination increases 366 environmental selection of bacteria containing clinical Class 1 integrons conferring resistance to both metals and antibiotics even in the absence of a selection pressure exerted by antibiotic residues.

4.3. Conclusions and perspectives for the environmental dissemination of ARGs.

Our findings provide evidence that metal contamination (As, $\mathrm{Cd}, \mathrm{Co}, \mathrm{Cr}, \mathrm{Cu}, \mathrm{Hg}, \mathrm{Ni}$ and $\mathrm{Zn}$ ) could

371 significantly affect the diversity, abundance and mobility potential of a broad spectrum of ARGs in urban

372 soils. Collectively, our results suggest that urban soil metal contamination increases the potential for

373 horizontal gene transfer of ARGs via co-selection of ARGs and MGEs thereby generating a pool of high-

374 risk mobile ARGs (Martínez et al., 2015). Indeed, it is likely that metals in many soils confer more

375 important selective agents than antibiotic residues because metals, as opposed to antibiotics, frequently

376 accumulate to persistent toxic levels in contaminated soils (Song et al., 2017). Based on the ongoing

377 recruitment of resistance genes by MGEs (Gillings et al., 2015, Gillings, 2018), we further hypothesize

378 that soil metals may become an even more important public health risk factor for the evolution (e.g.

379 selection, mobilization, transfer and persistence) of ARGs in the future. Hence, we call for additional

380 research into metal-induced co-selection of ARGs and MGEs in metal contaminated soils in the interest

381 of public health (Larsson et al., 2018).

382 Urban soils are commonly contaminated with toxic metals (McIlwaine et al., 2017) and our study thus has 383 implications for environmental regulation and management of urban soils worldwide. Hence, urban 384 residents may be exposed to ARGs via ingestion of metal-contaminated urban soils (especially children) 
or vegetables (urban gardening) unless adequate precautions are taken. Metals and co-selected ARGs may also be leached to groundwater or transported by surface runoff to aquatic receptors implying subsequent human ARG exposure via drinking water (Frey et al., 2015, Ma et al., 2017) or recreational activities (Leonard et al., 2018). Specific metals will probably co-select for different ARGs in different soils and it will therefore not be relevant to monitor only a few ARGs when evaluating risks posed by toxic soil metals. We therefore propose that metal susceptibility in indicator soil bacteria or absence of pollutioninduced community tolerance to metals (Lekfeldt et al., 2014) might serve as additional protection goals

392 for environmental risk assessment of toxic metals in soil. In conclusion, serious consideration is needed to 393 set minimum standards for retarding ARGs and for mitigating the accumulation of toxic metals in urban 394 soils.

\section{Supporting Information}

Identity of the 50 Tellus soil samples selected for this study (Table S1); primers used in this study (Table S2); relationships between geographical distance and distributions of antibiotic resistance genes (ARGs) and metal(loid) contamination as investigated by distance-decay analysis (Table S3); the ability of different land use categories to explain variation in ARG distribution by permanova test (Table S4); correlations between normalized abundance of clinical class 1 integron-integrase gene and total ARGs

402 (Table S5) (in Supporting Information.docx).

403 Shannon H index of 50 soil samples showing ARG diversity (Figure S1); stacked bar chart showed the 404 relative percentage of absolute abundance of ARGs (Figure S2); heatmap showing normalized abundance 405 of ARGs in 50 Tellus soils and their land use (Figure S3); heatmap showing absolute abundance of ARGs 406 in 50 Tellus soils and their land use (Figure S4); correlation between absolute abundances of class 1 407 integron/transposases and ARGs (Figure S5); correlations among metal toxicity index, MGEs and ARGs 408 (Figure S6) (in Supporting Information.docx). 


\section{Conflict of interests}

411 The authors declare no conflicts of interests.

\section{Acknowledgments}

414 The authors thank statistical advisory service provided by University of Copenhagen and Tianwei Xu for

415 the statistical advice on path analysis. Geochemistry data were provided by the Geological Survey of 416 Northern Ireland as part of the Tellus Project, which was funded by the Department of Enterprise, Trade 417 and Investment of Northern Ireland and by the EU 'Building Sustainable Prosperity' programme of the 418 Department of Agriculture and Rural Development. This work is supported financially by REMEDIATE 419 (Improved decision-making in contaminated land site investigation and risk assessment) Marie-Curie 420 Innovation Training Network from the European Union's Horizon 2020 Programme (grant number $421643087)$.

\section{References}

424 An XL, Chen QL, Zhu D, Zhu YG, Gillings MR, Su JQ, 2018. Impact of Wastewater Treatment on the Prevalence of Integrons and the Genetic Diversity of Integron Gene Cassettes. Appl Environ Microbiol, 84 (9): e02766-17

427 Ashbolt NJ, Amezquita A, Backhaus T, Borriello P, Brandt KK, Collignon P, et al, 2013. Human Health Environ Health Perspect, 121: 993-1001. 
Azarbad H, Niklinska M, Laskowski R, van Straalen NM, van Gestel CA, Zhou J, et al, 2015. Microbial community composition and functions are resilient to metal pollution along two forest soil gradients. FEMS Microbiol Ecol, 91: 1-11.

Baker-Austin C, Wright MS, Stepanauskas R, McArthur JV, 2006. Co-selection of antibiotic and metal resistance. Trends Microbiol, 14: 176-82.

Berendonk TU, Manaia CM, Merlin C, Fatta-Kassinos D, Cytryn E, Walsh F, et al, 2015. Tackling antibiotic resistance: the environmental framework. Nat Rev Microbiol, 13: 310-7.

Berg J, Brandt KK, Al-Soud WA, Holm PE, Hansen LH, Sørensen SJ, et al, 2012. Selection for Cutolerant bacterial communities with altered composition, but unaltered richness, via long-term $\mathrm{Cu}$ exposure. Appl Environ Microbiol, 78: 7438-7446.

Berg J, Thorsen MK, Holm PE, Jensen J, Nybroe O, Brandt KK, 2010. Cu exposure under field conditions coselects for antibiotic resistance as determined by a novel cultivation-independent bacterial community tolerance assay. Environ Sci Technol, 44(22):8724-8.

Brandt KK, Amézquita A, Backhaus T, Boxall A, Coors A, Heberer T, et al, 2015. Ecotoxicological assessment of antibiotics: a call for improved consideration of microorganisms. Environ Int, 85:189-205.

Brandt KK, Frandsen RJ, Holm PE, Nybroe O, 2010. Development of pollution-induced community tolerance is linked to structural and functional resilience of a soil bacterial community following a five-year field exposure to copper. Soil Biol Biochem, 42(5):748-57.

Dantas G, Sommer MOA, Oluwasegun RD, Church GM, 2008. Bacteria subsisting on antibiotics. Science 320 (5872):100-103.

D'Costa VM, Griffiths E, Wright GD, 2007. Expanding the soil antibiotic resistome: exploring environmental diversity. Curr Opin Microbiol 10 (5):481-489.

Deng W, Wang Y, Liu Z, Cheng H, Xue Y, 2014. HemI: a toolkit for illustrating heatmaps. PLoS One, 9: e111988. 
Eisenhauer N, Bowker MA, Grace JB, Powell JR, 2015. From patterns to causal understanding: Structural equation modeling (SEM) in soil ecology. Pedobiologia, 58: 65-72.

EMEA, 2006. European Medicines Agency, Guideline on the Environmental Risk Assessment of Medicinal Products for Human Use.

ESRI, 2010. Environmental Systems Resource Institute, ArcMap 10.0, Redlands, California.

European Environment Agency, 2012. Corine Land Cover 2012 seamless vector data.

Finney JM, 1972. Indirect effects in path analysis. Sociological Methods \& Research, 1: 175-186.

Forsberg KJ, Reyes A, Wang B, Selleck EM, Sommer MO, Dantas G, 2012. The shared antibiotic resistome of soil bacteria and human pathogens. Science, 337: 1107-1111.

Frey SK, Topp E, Khan IUH, Ball BR, Edwards M, Gottschall N, et al, 2015. Quantitative Campylobacter spp., antibiotic resistance genes, and veterinary antibiotics in surface and ground water following manure application: Influence of tile drainage control. Sci Total Environ 532:138-153.

Gillings M, Boucher Y, Labbate M, Holmes A, Krishnan S, Holley M, et al, 2008. The evolution of class 1 integrons and the rise of antibiotic resistance. J Bacteriol, 190: 5095-5100.

Gillings MR, Gaze WH, Pruden A, Smalla K, Tiedje JM, Zhu YG, 2015. Using the class 1 integronintegrase gene as a proxy for anthropogenic pollution. ISME J, 9: 1269-1279.

Gillings MR, 2018. DNA as a Pollutant: the Clinical Class 1 Integron,. Current Pollution Reports, $4(1): 49-55$.

Graham DW, Knapp CW, Christensen BT, McCluskey S, Dolfing J, 2016. Appearance of $\beta$-lactam resistance genes in agricultural soils and clinical isolates over the 20th century. Sci Rep 6:21550.

Hammer $\emptyset$, Harper D, Ryan P, 2001. Paleontological statistics software: package for education and data analysis. Palaeontol Electron, 4(1):9-178

Hoffman LR, D'Argenio DA, MacCoss MJ, Zhang Z, Jones RA, Miller SI, 2005. Aminoglycoside antibiotics induce bacterial biofilm formation. Nature, 436: 1171-5. 
Imfeld G, Bringel F, Vuilleumier S, 2011. Bacterial tolerance in contaminated soils: potential of the PICT approach in microbial ecology. Tolerance to Environmental Contaminants, CRC, Boca Raton, pp341-370.

Knapp CW, Callan AC, Aitken B, Shearn R, Koenders A, Hinwood A, 2017. Relationship between antibiotic resistance genes and metals in residential soil samples from Western Australia. Environ Sci Pollut Res Int, 24: 2484-2494.

Knapp CW, McCluskey SM, Singh BK, Campbell CD, Hudson G, Graham DW, 2011. Antibiotic resistance gene abundances correlate with metal and geochemical conditions in archived Scottish soils. PLoS One, 6: e27300.

Knapp CW, Dolfing J, Ehlert PA, Graham DW, 2010. Evidence of increasing antibiotic resistance gene abundances in archived soils since 1940. Environ Sci Technol, 44(2):580-587.

Knights KV, 2006. A report on the Tellus urban field campaigns of Belfast Metropolitan areas and Londonderry. Commissioned Report CR/07/006N. British Geological Survey.

Larsson DGJ, Andremont A, Bengtsson-Palme J, Brandt KK, de Roda Husman AM, Fagerstedt P, et al, 2018. Critical knowledge gaps and research needs related to the environmental dimensions of antibiotic resistance. Environ Int 117:132-138.

Lekfeldt JDS, Magid J, Holm PE, Nybroe O, Brandt KK, 2014. Evaluation of the leucine incorporation technique for detection of pollution-induced community tolerance to copper in a long-term agricultural field trial with urban waste fertilizers. Environ Pollut 194:78-85.

Leonard AFC, Zhang L, Balfour AJ, Garside R, Hawkey PM, Murray AK, et al, 2018. Exposure to and colonisation by antibiotic-resistant E. coli in UK coastal water users: Environmental surveillance, exposure assessment, and epidemiological study (Beach Bum Survey). Environ Int 114:326-333.

Li G, Sun GX, Ren Y, Luo XS, Zhu YG, 2018. Urban soil and human health: a review. Eur J Soil Sci, 69: 196-215.

Looft T, Johnson TA, Allen HK, Bayles DO, Alt DP, Stedtfeld RD, et al, 2012. In-feed antibiotic effects on the swine intestinal microbiome. Proc Natl Acad Sci USA, 109: 1691-6. 
Luo XS, Yu S, Zhu YG, Li XD, 2012. Trace metal contamination in urban soils of China. Sci Total Environ, 421-422: 17-30.

Ma L, Li B, Jiang XT, Wang YL, Xia Y, Li AD, Zhang T, 2017. Catalogue of antibiotic resistome and host-tracking in drinking water deciphered by a large scale survey. Microbiome 5 (1):154, 2017.

Martínez JL, Coque TM, Baquero F, 2015. What is a resistance gene? Ranking risk in resistomes. Nat Rev Microbiol, 13(2):116.

Mata M, Baquero F, Perez - Diaz J, 2000. A multidrug efflux transporter in Listeria monocytogenes. FEMS Microbiol Lett, 187: 185-188.

McIlwaine R, Doherty R, Cox SF, Cave M, 2017. The relationship between historical development and potentially toxic element concentrations in urban soils. Environ Pollut, 220: 1036-1049.

McLaughlin MJ, Smolders E, 2001. Background zinc concentrations in soil affect the zinc sensitivity of soil microbial processes-A rationale for a metalloregion approach to risk assessments. Environ Toxicol Chem, 20: 2639-2643.

NISRA, 2016. Population Projections for areas within Northern Ireland: 2016-based. Northern Ireland Statistics and Research Agency.

Oksanen J, Kindt R, Legendre P, O’Hara B, Stevens MHH, Oksanen MJ, et al, 2007. The vegan package. Community ecology package, 10: 631-637.

Pal C, Asiani K, Arya S, Rensing C, Stekel DJ, Larsson DGJ, et al, 2017. Metal Resistance and Its Association With Antibiotic Resistance. Adv Microb Physiol, 70: 261-313.

Pal C, Bengtsson-Palme J, Kristiansson E, Larsson DG, 2015. Co-occurrence of resistance genes to antibiotics, biocides and metals reveals novel insights into their co-selection potential. BMC Genomics, 16: 964.

Partridge SR, Tsafnat G, Coiera E, Iredell JR, 2009. Gene cassettes and cassette arrays in mobile resistance integrons. FEMS Microbiol Rev, 33: 757-84. 
Pruden A, Pei R, Storteboom H, Carlson KH, 2006. Antibiotic resistance genes as emerging contaminants: studies in northern Colorado. Environ Sci Technol, 40: 7445-7450.

Rousk J, Bååth E, Brookes PC, Lauber CL, Lozupone C, Caporaso JG, Knight R, Fierer N, 2010. Soil bacterial and fungal communities across a pH gradient in an arable soil. ISME J, 4(10):1340.

Royle SA, Simms A, Clarke HB, Gillespie R, 2007. Belfast, Part II, 1840-1900. Royal Irish Academy. SCENIHR, 2009. SCoEaNIHR. Assessment of the Antibiotic Resistance Effects of Biocides.

Seiler C, Berendonk TU, 2012. Heavy metal driven co-selection of antibiotic resistance in soil and water bodies impacted by agriculture and aquaculture. Front Microbiol, 3: 399.

Shannon P, Markiel A, Ozier O, Baliga NS, Wang JT, Ramage D, et al, 2003. Cytoscape: a software environment for integrated models of biomolecular interaction networks. Genome Res, 13: 24982504.

Smolders E, Oorts K, Van Sprang P, Schoeters I, Janssen CR, McGrath SP, McLaughlin MJ, 2009. Toxicity of trace metals in soil as affected by soil type and aging after contamination: using calibrated bioavailability models to set ecological soil standards. Environ Toxicol Chem, 28(8):1633-42.

Smyth D, 2007. Methods used in the Tellus geochemical mapping of Northern Ireland. British Geological Survey open report OR/07/022, http://nora.nerc.ac.uk/14008/.

Song J, Rensing C, Holm PE, Virta M, Brandt KK, 2017. Comparison of Metals and Tetracycline as Selective Agents for Development of Tetracycline Resistant Bacterial Communities in Agricultural Soil. Environ Sci Technol, 51: 3040-3047.

Stefanowicz AM, Niklińska M, Laskowski R, 2008. Metals affect soil bacterial and fungal functional diversity differently. Environ Toxicol Chem, 27(3):591-8.

Tzeneva VA, Salles JF, Naumova N, de Vos WM, Kuikman PJ, Dolfing J, et al, 2009. Effect of soil sample preservation, compared to the effect of other environmental variables, on bacterial and eukaryotic diversity. Res Microbiol, 160: 89-98. 
United Nations, 2014. Department of Economic and Social Affairs Population Division. World Urbanization Prospects: the 2014 Revision. Highlights (ST/ESA/SER.A/352), United Nations.

557 Ventola CL, 2015. The antibiotic resistance crisis: part 1: causes and threats. Pharm Ther, 40: 277.

558 Wang FH, Qiao M, Su JQ, Chen Z, Zhou X, Zhu YG, 2014. High throughput profiling of antibiotic

559 resistance genes in urban park soils with reclaimed water irrigation. Environ Sci Technol, 48:

$560 \quad 9079-85$

561 Welp G, 1999. Inhibitory effects of the total and water-soluble concentrations of nine different metals on 562 the dehydrogenase activity of a loess soil. Biol Fertil Soils, 30(1-2):132-9.

563 Yazdankhah S, Rudi K, Bernhoft A, 2014. Zinc and copper in animal feed - development of resistance 564 565 566 567 568 569 with antibiotic resistance genes. Nat Microbiol, 2: 16270. 
575

Figure 1 Antibiotic resistance gene (ARG) profile in Belfast urban soils. The map (a) reveals the number of different ARGs detected (dot size scale) and their absolute abundance (copies per gram of soil; color scale) in 50 urban soils from the Belfast metropolitan area. Pie charts depict (b) the percentage of detected ARGs corresponding to different resistance mechanisms and (c) their classification based on the antibiotics they confer resistance to.

Figure 2 Correlation between mobile genetic elements (MGEs) and antibiotic resistance genes (ARGs) across all 50 Belfast urban soils. (a) The normalized abundance of all targeted MGEs (2 integrons and 8 transpons) significantly correlated to the total number of detected ARGs and the normalized abundance of ARGs (copies per 16S rRNA gene) based on Pearson's correlation $(P<0.001)$. (b) Network analysis showing the co-occurrence pattern between individual MGEs and ARGs. A connection represents a strong (Pearson's $r>0.7)$ and significant $(P<0.05)$ correlation. The nodes with different colors represent MGEs and different ARG types. The edges with different colors correspond to positive (grey) and negative (red) correlations between nodes. The size of node is proportional to the number of connections between nodes. The width of edge is proportional to the degree of correlation.

Figure 3 Network analysis showing the co-occurrence pattern between metals ( $\mathrm{As}, \mathrm{Cd}, \mathrm{Co}, \mathrm{Cr}, \mathrm{Cu}, \mathrm{Hg}$, $\mathrm{Ni}, \mathrm{Pb}$, and $\mathrm{Zn}$ ) and antibiotic resistance genes (ARGs) based on Pearson correlation analysis. A connection represents a strong (Pearson's $r>0.7)$ and significant $(P<0.05)$ correlation. The color of each node represents each metal or the type of ARG. The node size is proportional to the number of the connections. The edge width represents the degree of correlation plotted with Pearson's r. All significant correlations in the data set were positive.

Figure 4 Path analysis showing the modelled effect of soil metal contamination (metal toxicity index) and normalized abundance of mobile genetic elements(MGEs) on (a) the number of detected antibiotic resistance genes (ARGs) and the normalized abundance of co-occurring ARGs (copies per 16S rRNA 
598 gene). Path arrows correspond to positive (red) and negative (green) effects with significance level of $P<$ 5990.05 (solid line), and $P>0.05$ (dotted line) with path directions. Numbers adjacent to the path arrows are 600 path coefficients (standardized regression weights), and the arrow width is proportional to the strength of 601 path coefficients. Bar charts show the standardized direct effect, indirect effect and total effect of metal 602 toxicity index and MGEs on (b) number of detected ARGs and (c) normalized abundance of co-occurring 603 ARGs (copies per 16S rRNA gene) derived from path modelling (a). 
Table 1 Total concentrations of metals in Belfast urban soils.

\begin{tabular}{lllll}
\hline Symbol & Name & Average $(\mathrm{mg} / \mathrm{kg})$ & Min - Max $(\mathrm{mg} / \mathrm{kg})$ & Category \\
\hline $\mathrm{Pb}$ & Lead & 354.5 & $22.9-2910$ & Post-transition metal \\
$\mathrm{Cd}$ & Cadmium & 0.8 & $0.08-3.27$ & Transition metal \\
$\mathrm{Co}$ & Cobalt & 22.3 & $6.1-48$ & Transition metal \\
$\mathrm{Cr}$ & Chromium & 64.1 & $24-345$ & Transition metal \\
$\mathrm{Cu}$ & Copper & 160.0 & $19-954$ & Transition metal \\
$\mathrm{Hg}$ & Mercury & 0.4 & $0.06-1.86$ & Transition metal \\
$\mathrm{Ni}$ & Nickel & 82.3 & $20.1-244$ & Transition metal \\
$\mathrm{Zn}$ & Zinc & 458.4 & $32-5550$ & Transition metal \\
$\mathrm{As}$ & Arsenic & 14.1 & $2.2-51.3$ & Metalloid \\
\hline
\end{tabular}

*Analyzed with aqua regia digestion followed by Inductively Coupled Plasma Mass Spectrometry (ICP-MS) (McIlwaine et al., 2017). 

○ 8 - 28
O 29-50
O 51-100
O $101-137$

Abundance of total ARGs (copies per gram of soil)

$678-6.4 \times 10^{6}$ $6.4 \times 10^{6}-3.3 \times 10^{7}$

$3.3 \times 10^{7}-8.6 \times 10^{7}$

$8.6 \times 10^{7}-1.6 \times 10^{8}$ b

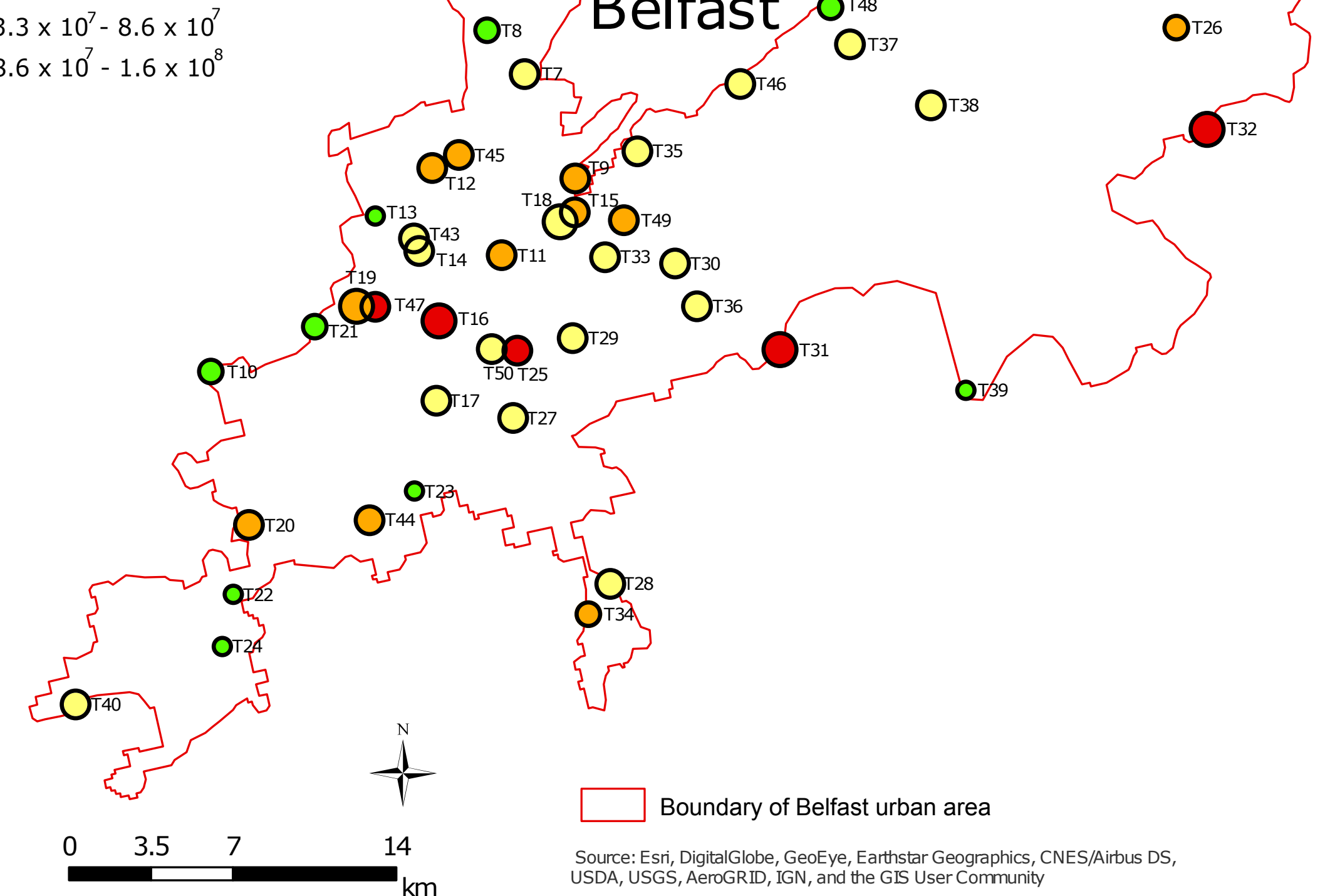

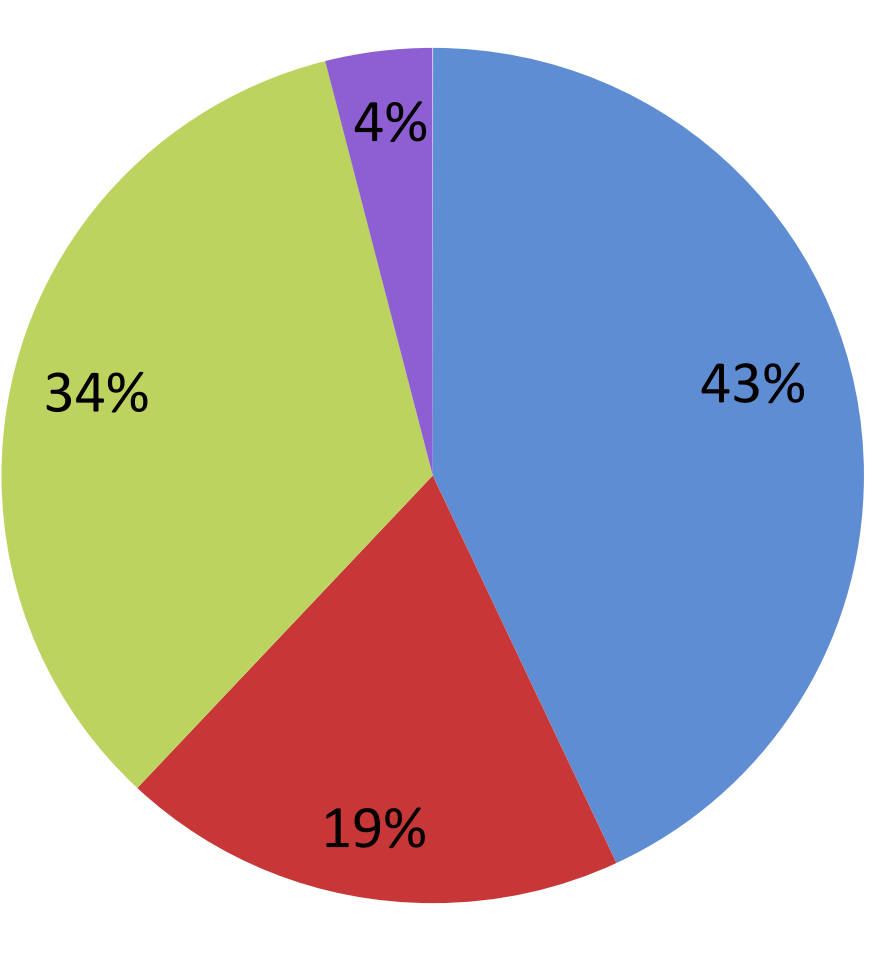

Antibiotic deactivation

- Cellular protection

Efflux pump

Other/unknown
C

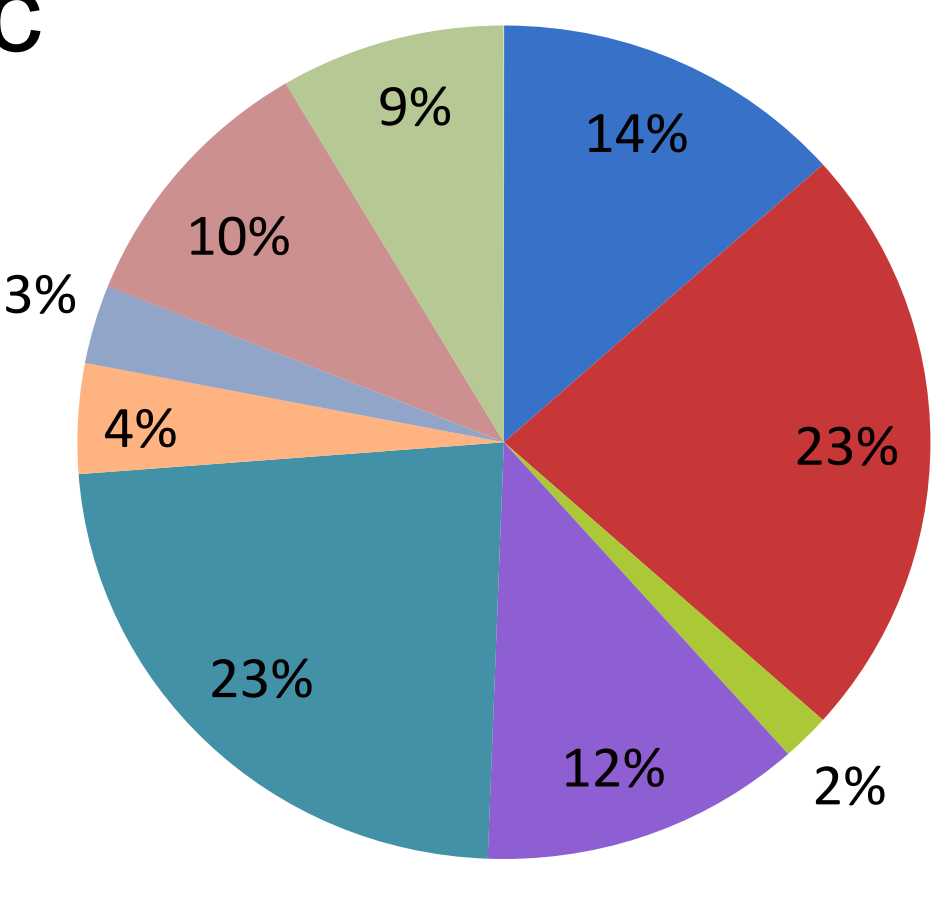

Aminoglycoside

- Beta-lactam

Chloramphenicol

- MLSB

- Multidrug

Sulfonamide

- Tetracycline

Vancomycin

Others 


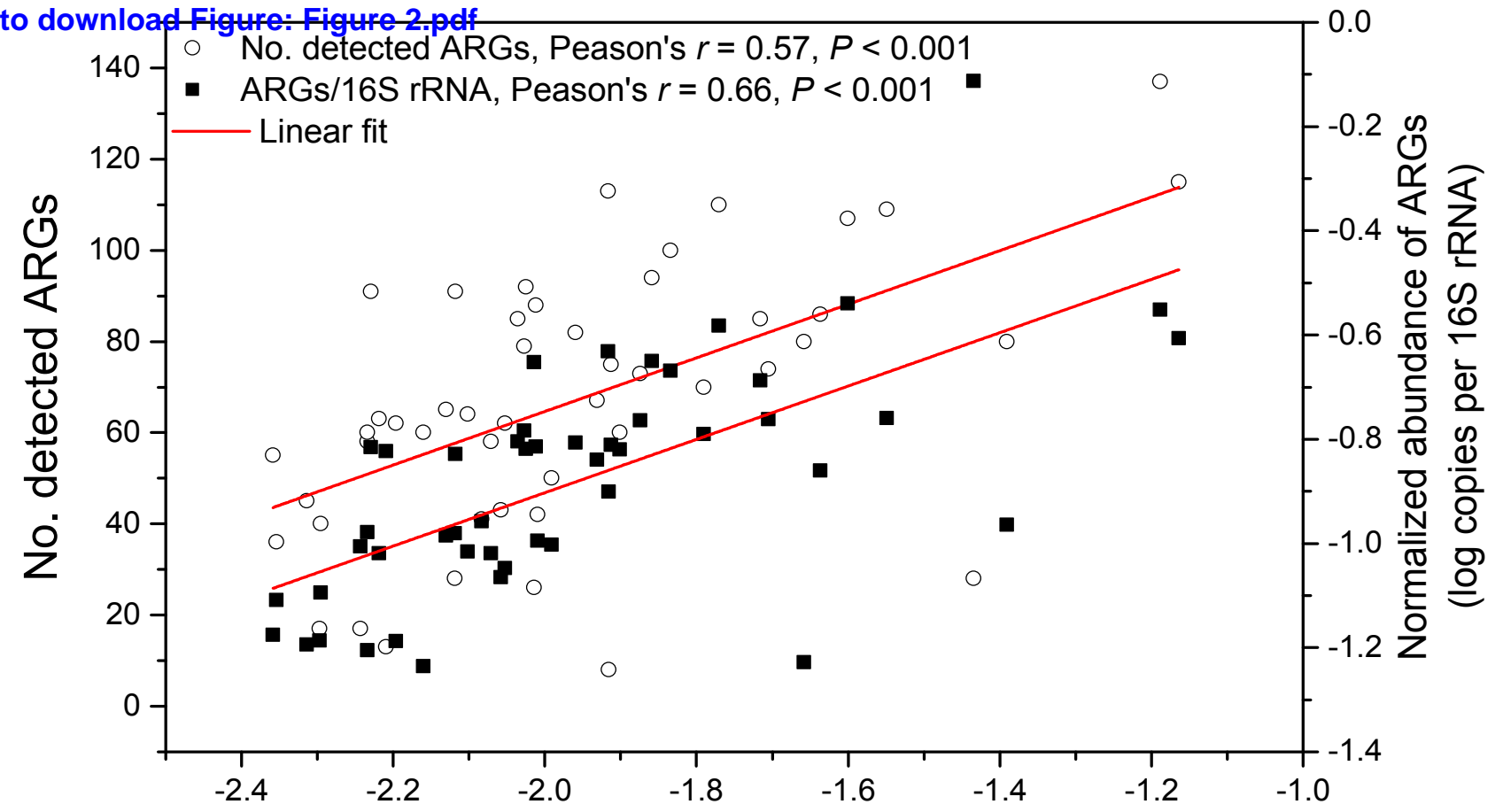

Normalized abundance of MGEs

(log copies per 16S rRNA)

b

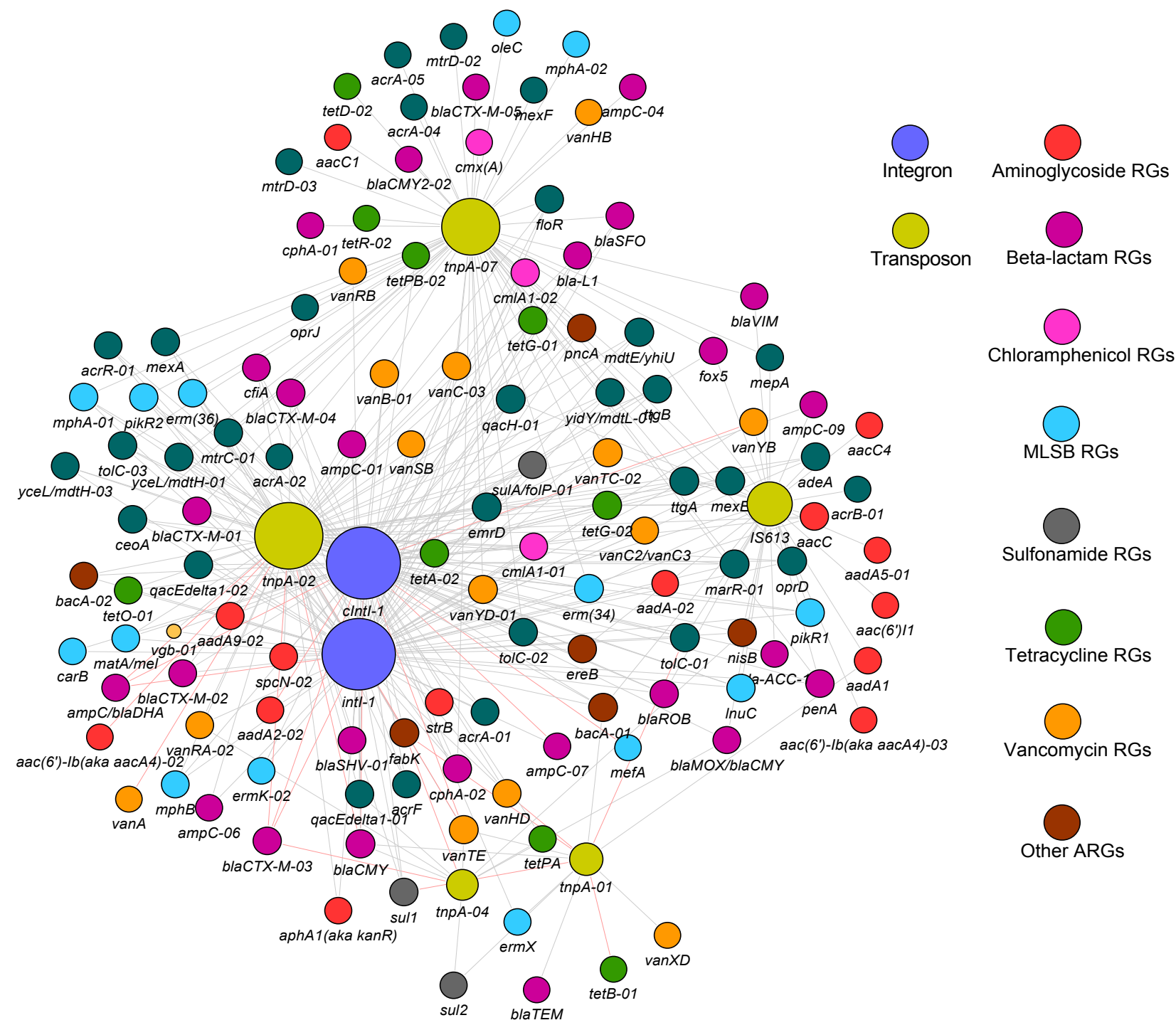


Click here to download Figure: Figure 3.pdf Metals

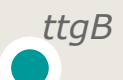

$\operatorname{aad} A 1$

Aminoglycoside RGs

Beta-Lactam RGs

MLSB RGs

Multidrug RGs

Tetracycline RGs

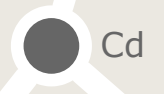

$\bigcirc \mathrm{Ni}$ aadA-02

adeA

\section{qacEdelta1-02}

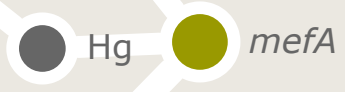

strB

blaMOX/blaCMY

Vancomycin RGs

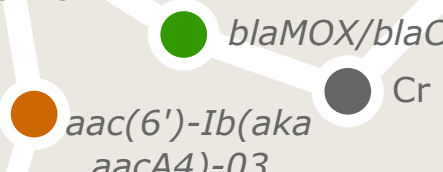

ampC-07

tetPB-03

aadA5-01

rarD-02 As 
$\Rightarrow$ : Positive effect

$\Rightarrow$ : Negative effect

$\longrightarrow$ : paths with $P<0.05$

$\longrightarrow$ : paths with $P>0.05$

Goodness-of-fit-model > 0.95

Degree of freedom (df) : 1

Chi-square $=1.226(P>0.05)$

RMSEA $<0.08$

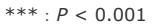

$* *: P<0.01$

* $: P<0.05$ ARGs

\section{co-occurring} ARGs

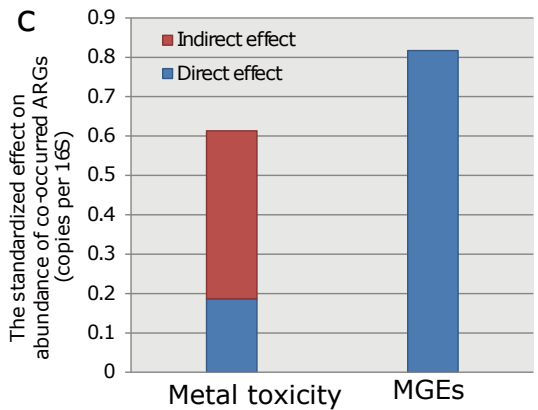

b

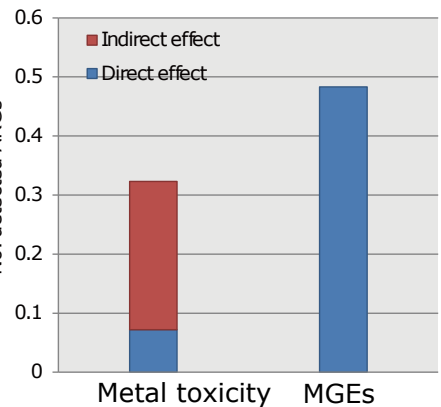



Supplementary material for on-line publication only
Click here to download Supplementary material for o Click here to download Supplementary material for on-line publication only: Supporting Information.docx 